\title{
Aptness predicts preference for metaphors or similes, as well as recall bias
}

\author{
DAN L. CHIAPPE \\ University of British Columbia, Vancouver, British Columbia, Canada \\ and \\ JOHN M. KENNEDY \\ University of Toronto, Scarborough, Ontario, Canada
}

\begin{abstract}
Why might we sometimes prefer a metaphor such as "genes are blueprints" to a simile such as "genes are like blueprints"? One possibility is that metaphors are preferred when the comparison between a tenor (e.g., genes) and a vehicle (e.g., blueprints) seems especially apt. That is, metaphors might be used when the comparison captures many salient features of the tenor in question. The present experiments examined the relation between the aptness of comparisons and people's preferences for expressing those comparisons as metaphors or as similes. In Experiment 1, it was found that there is consensus on how to express particular comparisons. In Experiment 2, it was found that this preference can be predicted from the aptness of a comparison. It was also found that aptness can predict errors in the recall of comparisons. These findings have implications for theories of metaphor.
\end{abstract}

Metaphors and similes are distinct but closely related literary devices, or tropes. Metaphors, such as "rumors are weeds," assert an identity between two domains. To use I. A. Richards's (1936) terms, they assert an identity between the tenor and the vehicle. The tenor is the subject of the statement ("rumors" in "rumors are weeds"), and the vehicle is the concept that we are using in order to say something new about the tenor ("weeds" in "rumors are weeds"). Similes, such as "rumors are like weeds," assert a similarity between the tenor and the vehicle, not an identity relation.

The relation between metaphors and similes has long been the subject of debate. What is sure is that, despite their differences, metaphors and similes share important functions. Certainly, both tropes are used to convey information about their topics. A brief vehicle often acts as a handy summary, as when one says "In short, this article is a goldmine." Furthermore, it is often argued that metaphors and similes might be used when people want to convey information about a topic that cannot be explicitly stated in literal language (Fogelin, 1988; Gibbs, 1994; Ortony, 1975). For example, a person might use the metaphor "my job is a jail" or the simile "my job is like

This research was made possible by NSERC Grant OGP9947 to J.M.K. The authors thank Penny Chiappe and Chang Hong Liu for their advice on statistical matters. They also thank Heather Benson for her assistance in data collection and Hiroshi Ono and graduate students from York University for their participation in Experiment 1. Finally, the authors thank Psychonomic Bulletin \& Review referees for useful suggestions, including a helpful argument about nonsensical comparisons. Correspondence concerning this article should be addressed to J. M. Kennedy, University of Toronto, 1265 Military Trail, Scarborough, ON M1C1A4, Canada (e-mail: kennedy@lake.scar. utoronto.ca). a jail" to convey that their job possesses an intricate system of properties that is difficult to state explicitly (Glucksberg \& Keysar, 1993).

In this paper, we ask about a factor that could play a major role in determining whether a comparison is expressed as a metaphor or as a simile. For example, why might a person express a comparison between genes and blueprints with the metaphor "genes are blueprints" rather than with the simile "genes are like blueprints"? And, why might a person express a comparison between treetrunks and straws with the simile "treetrunks are like straws" rather than with the metaphor "treetrunks are straws"? We examine whether the preference for one form of a comparison is simply idiosyncratic and whether the choice reflects important differences between metaphors and similes.

Before turning to our major hypothesis, let us acknowledge that there is a role played here by custom. Through use, certain comparisons become more familiar to people as metaphors or as similes. As a result, people might choose to express the comparisons in their more familiar form. For example, Robert Burns's comparison "my love is like a red, red rose" is most familiar as a simile. As a result, followers of Burns might strongly prefer to express this comparison as a simile rather than as the metaphor "my love is a red, red rose." Likewise, the metaphor "God is love" is quite familiar in our culture. "God is like love" is quite unfamiliar and, to many, may seem peculiar. Hence, many might choose to express the comparison as a metaphor. In short, one form of expression may become entrenched in a language and, thereby, affect how a comparison is subsequently expressed.

Familiarity, however, cannot account for how all comparisons are expressed, because many comparisons are 
created de novo. Some factor or factors other than familiarity may have determined how a comparison was expressed in the first place. But what?

In the present experiments, aptness was examined. We followed much of the recent literature on metaphor and defined aptness as the extent to which a comparison captures salient features of the topic in question (Katz, 1989, 1992; Malgady \& Johnson, 1976; Tourangeau \& Sternberg, 1981, 1982; Trick \& Katz, 1986). Consider, for example, "evolution is a lottery" and "evolution is a blind watchmaker." In both of these comparisons, the tenor and the vehicle share relevant features. Evolution involves randomness and lack of foresight. Also, evolution involves the emergence of admirable structures. But one of the comparisons captures more features than the other, and for some purposes, it may be necessary to draw attention to many features of the tenor. The comparison that captures the appropriate number of relevant features could be considered especially apt.

It may be helpful if we expand on our example to make our point clear. For many readers of recent arguments about evolution, "evolution is a lottery" might not appear very apt, because the comparison fails to capture the constructive aspect of evolution (Dawkins, 1986). In contrast, "evolution is a blind watchmaker" captures both the process and the product. Therefore, it could appear to many to be a more apt comparison.

The difference between "lotteries" and "blind watchmakers" is largely one of content. Would it make any difference if the form of expression of the comparison was varied? Is "evolution is like a lottery" to be preferred to "evolution is a lottery"? If so, is the preference related to the apparent aptness of the comparison? For example, if a comparison is deemed very appropriate, are people more likely to judge that it is best expressed as a metaphor? And if a comparison is deemed not very appropriate, are people more likely to judge that it is best expressed as a simile?

In the traditional theory of metaphor that has come down to us from Aristotle (1926), we find little guidance on the preference for one form of expression over another. In particular, Aristotle's theory offers no prediction about the relation between the aptness of a comparison and any tendency to express it as a metaphor or as a simile. If anything, the Aristotelian theory claims that there is no such relation. For Aristotle, metaphors are similes with the term of comparison - the like--left out (modern proponents of this view include Fogelin, 1988; Gentner, 1983, 1989; Gentner \& Clement, 1988; Gentner \& Markman, 1997; Miller, 1979; Ortony, 1979a, 1979b; and Tversky, 1977). In this view, the only difference between a metaphor and a simile is that the metaphor is a more compact statement. As Aristotle said, "[The] simile ... is a metaphor differing only by the addition of a word" (p. 397). As a result, one's preference for expressing a comparison as a metaphor or as a simile should be determined by whether or not one wants to be concise. There is no explicit basis in the Aristotelian theory for arguing that the preference should be guided by the aptness of the comparison.

In contrast, recent theorists have contended that the form of the comparison is more than a matter of brevity (Black, 1979; Morgan, 1979). For example, Glucksberg and Keysar $(1990,1993)$ claim that there is a relation between a person's beliefs and the form in which a comparison is expressed. As an example, they compare the simile "my job is like a jail" to the metaphor "my job is a jail." They say, "When the metaphorical form is chosen over the simile form, the very choice is communicative. If one chooses the simile, then the hearer presumably recognizes that choice and would therefore infer that the speaker was not attributing all the properties of the class 'jail' to 'my job,' but only some of them" (1993, p. 413). Alternatively, if a person chooses the metaphor, "the intention is for the hearer to understand that the job in question has all the properties of the attributive category that is called "jail'" (1993, p. 413). Hence, according to Glucksberg and Keysar $(1990,1993)$, similes are used when a comparison is not deemed to be what we have called very apt; when a comparison is very apt, the metaphorical form is preferred. As Roberts and Kreuz (1994) say, following Glucksberg and Keysar, "a simile may aid a listener in determining that a comparison is not intended quite as seriously" (p. 162).

In short, the literature is divided. Proponents of the Aristotelian theory (including, among others, Fogelin, 1988, and Miller, 1979) do not offer grounds for predicting a relation between aptness and the form in which a comparison is expressed, but Glucksberg and Keysar (1990, 1993) and Roberts and Kreuz (1994) do.

The present experiments tested the relation between aptness and the preferred form of comparisons. In Experiment 1 , we examined whether there is consensus between people on how a particular comparison should be expressed. This was done by presenting subjects with pairs of metaphors and similes and asking them to indicate which was the best way of expressing each of the comparisons.

In Experiment 2, we explored two issues. First, we examined whether the preference for the metaphor or the simile form of comparisons found in Experiment 1 could be predicted from the aptness of those comparisons, as rated by a separate group of subjects. Second, we exan ined whether the aptness of comparisons could predict performance on a cued-recall task. A cued-recall task was used as an indirect measure of people's preferences for expressing comparisons as metaphors or as similes. This is because, as Schacter (1995) says, "information available in the present retrieval environment combines with stored information to yield an emergent pattern of activity that we experience as "memory"' (p. 24). Thus, recall is usually influenced by constructive processes (Bartlett, 1932; Neisser, 1967). Any preference for one type of comparison could therefore play a role during recall and could be evident in the form of a bias to recall a comparison as a metaphor or as a simile, regardless of 
the form in which one initially saw the comparison. For example, if a comparison between smiles and razors is not very apt, people might be more likely to misrecall "smiles are razors" as "smiles are like razors" than the reverse. However, if a comparison between genes and blueprints is especially apt, people might be more likely to misrecall "genes are like blueprints" as "genes are blueprints" than the reverse.

\section{EXPERIMENT 1}

In Experiment 1, we examined whether there is a consensus between individuals on whether particular comparisons are best expressed as metaphors or as similes. Is preference merely idiosyncratic? If not, what is the preferred form? The subjects were shown the metaphor and the simile forms of several comparisons and were asked to indicate which form best expressed the comparison.

\section{Method}

Subjects. Thirty subjects ( 24 female and 6 male), with a mean age of 23 years, participated in this experiment. There were two groups, to provide a check on the replicability of the results. Twentyone subjects were volunteers from a third-year course in psychology at the University of Toronto at Scarborough. Nine subjects were graduate student volunteers from York University. The subjects were tested either individually or in pairs.

Stimuli and Apparatus. The subjects were shown 30 comparisons in both their metaphor and their simile forms. This yielded a total of 60 statements. The statements-listed in Table 1 -were drawn from various sources in the psychological literature on figurative representation. Items were presented in booklets that had instructions on the front page and one page with 30 pairs of metaphors and similes. Thus, each metaphor was presented with its corresponding simile. The order of the metaphors and similes was randomized, so that half of the time the metaphors appeared first, and half of the time the similes appeared first. The number " 1 " was written beside the comparisons appearing first, and the number " 2 " beside the ones appearing second. The order of the 30 comparisons was also randomized, with one random order for each subject.

Procedure. The subjects were given the booklets containing the 30 pairs of metaphors and similes. The subjects were told to read each pair of statements and then decide whether the metaphor or the simile best expressed the comparison in question. For example, they were asked whether a comparison between priests and shepherds is best expressed by the metaphor "priests are shepherds" or by the simile "priests are like shepherds." The subjects responded by circling the number written beside the statement of their choice.

\section{Results and Discussion}

This experiment used two groups: undergraduates and graduate students, with each group drawn from a different institution. Did the two groups respond in a similar way? We examined whether the preferences of one group could predict the preferences of the other group. The analysis revealed a correlation of $.78(p<.005)$. When one group preferred the metaphor form of a comparison, the other group was also likely to prefer the metaphor. And when one group preferred the simile form, the other group was also likely to prefer the simile. Evidently, there was agreement between the two groups. Consequently,
Table 1

Levels of Consensus, Metaphor Preference, and Mean Aptness for 30 Comparisons

\begin{tabular}{|c|c|c|c|}
\hline Statement & Consensus & $\begin{array}{l}\text { Metaphor } \\
\text { Preference }\end{array}$ & $\begin{array}{r}\text { Mean } \\
\text { Aptnes }\end{array}$ \\
\hline Life is (like) a journey & .97 & .97 & 6.40 \\
\hline Highways are (like) snakes & .97 & .03 & 3.48 \\
\hline People are (like) doors & .93 & .07 & 2.84 \\
\hline Tree trunks are (like) straws & .90 & .10 & 3.75 \\
\hline Smiles are (like) razors & .90 & .10 & 2.65 \\
\hline Trees are (like) umbrellas & .90 & .10 & 4.73 \\
\hline Cigarettes are (like) time bombs & .87 & .87 & 5.05 \\
\hline Genes are (like) blueprints & .87 & .87 & 6.31 \\
\hline Giraffes are (like) skyscrapers & .87 & .13 & 5.07 \\
\hline Jobs are (like) jails & .83 & .17 & 3.90 \\
\hline Man is (like) a wolf & .80 & .20 & 3.03 \\
\hline Billboards are (like) warts & .80 & .20 & 2.89 \\
\hline Hearts are (like) closets & .77 & .23 & 3.49 \\
\hline Desks are (like) junkyards & .77 & .23 & 4.16 \\
\hline Education is (like) a stairway & .70 & .70 & 5.43 \\
\hline Crime is (like) a disease & .67 & .67 & 5.49 \\
\hline Words are (like) daggers & .67 & .33 & 4.27 \\
\hline Salesmen are (like) bulldozers & .67 & .33 & 4.12 \\
\hline Sermons are (like) sleeping pills & .67 & .33 & 4.47 \\
\hline Deserts are (like) ovens & .67 & .33 & 5.25 \\
\hline Arguing is (like) war & .63 & .37 & 4.88 \\
\hline Encyclopedias are (like) goldmines & .60 & .60 & 5.07 \\
\hline Nature is (like) a laboratory & .60 & .60 & 4.73 \\
\hline Mosquitos are (like) vampires & .60 & .40 & 5.50 \\
\hline Surgeons are (like) butchers & .60 & .40 & 4.42 \\
\hline Alcohol is (like) a crutch & .57 & .57 & 3.80 \\
\hline Indecision is (like) a whirlpool & .57 & .43 & 4.78 \\
\hline Friends are (like) anchors & .53 & .53 & 4.62 \\
\hline (like) diamonds & .53 & .47 & 4.72 \\
\hline Roosters are (like) alarm clocks & .53 & .47 & 5.47 \\
\hline
\end{tabular}

Note-An analysis of critical ratios shows that when $N=30$, levels of consensus greater than or equal to .70 are above chance $(\mathrm{CR}=2.01$, $p<.05$ ).

they can be collapsed into one group for consideration of the level of consensus on each comparison.

The level of consensus for each comparison was determined by the size of the majority that agreed on whether the comparison should be expressed as a metaphor or as a simile. For example, the proportion of subjects that preferred the metaphor "crime is a disease" was .67 (and the simile .33, of course). The proportion of subjects that preferred the simile "man is like a wolf" was .80 (and the metaphor "man is a wolf" was .20). The consensus levels for these comparisons are .67 and .80 , respectively.

Across the 30 comparisons, the mean consensus level was .73 $(S D=.14)$. This level of consensus is not ran$\operatorname{dom}[t(29)=8.90, p<.0001]$. Hence, in general, there was significant agreement between subjects on how a comparison should be expressed. However, the consensus was stronger for some items than for others. Usefully, the consensus (shown in Table 1) covered the range from random (e.g., .53 for "friends/anchors," as a metaphor) to close to unanimous (e.g., .97 for "life/journey," as a metaphor). An analysis of critical ratios (CRs) shows that when $N=30$, consensus levels of .70 and greater are above chance on a two-tailed test $(\mathrm{CR}=2.01, p<.05)$. 
As Table 1 shows, the proportion of subjects preferring the comparisons as metaphors ranged from .03 ("highways/ snakes") to .97 ("life/journey"). Nine of the items were preferred as metaphors, while 21 items were preferred as similes. (Preference was determined by the form the majority of subjects chose. There were no ties.) However, because only consensus levels greater than or equal to .70 were significant, preference for comparison type was significant for only 15 of the items ( 11 similes and 4 metaphors).

The mean proportion of metaphors chosen was .39 $(S D=.25)$. This was significantly less than chance $[t(29)=2.31, p<.05]$. So, subjects generally preferred the simile form of a comparison over the metaphor form. (This is useful, since it is an indicator that we had not selected stimuli from the literature on metaphors that have generally become well established in the form of metaphors in our culture and were preferred for that reason alone.)

To summarize, Experiment 1 revealed a significant consensus between subjects on how some comparisons are best expressed. Some of the comparisons were judged to be best expressed as similes, others as metaphors, whereas for other comparisons, there was no clear preference for either the metaphor or the simile form. The range of consensus was essentially from chance to unanimity.

\section{EXPERIMENT 2}

In Experiment 1, we found that people prefer some comparisons as metaphors, others as similes, and for still others, there is no clear preference across subjects. In Experiment 2, we examined whether preference reflects the aptness of comparisons. We also examined whether the relation between aptness and the form of a comparison can be revealed through an influence on a cognitive task. In particular, can it affect how comparisons are recalled?

In the first part of the experiment, the subjects had to rate the comprehensibility of a set of metaphors and similes. This study phase was followed by a surprise cuedrecall task, in which the subjects had to recall the comparisons they had seen and the form in which they had seen them (i.e., whether they had seen them as metaphors or as similes). As a final task, the subjects had to rate the aptness of the comparisons.

If comparisons that are high in aptness are preferred as metaphors and comparisons that are low in aptness are preferred as similes, two predictions follow. The lower the aptness of a comparison, the more likely it is that people should misrecall the metaphors as similes, and the higher the aptness of a comparison, the more likely it is that people should misrecall the similes as metaphors.

\section{Method}

Subjects. Forty-six subjects ( 14 males and 32 females), with a mean age of 24 years, participated in this experiment. The subjects were volunteers from a second-year course in psychology. All the students were from the University of Toronto at Scarborough. The subjects were tested individuaily.

Stimuli and Apparatus. The stimuli were the same statements as those used in Experiment 1. The subjects only saw one version of each statement. All of the instructions for this study were presented on an IBM-compatible computer.

Procedure. In the first part of the experiment, the study phase, the subjects were shown 15 metaphors and 15 similes, one at a time. The items were presented in a different random order for each subject. The subjects were told to read each statement and to rate them for their comprehensibility. By keypress, they had to give their estimate of how easy each statement is to understand, using a scale from 1 (very incomprehensible) to 7 (very comprehensible). A comprehensibility judgment task was used because it was likely to get the subjects to pay attention to the meaning of each comparison, a task that favors recall of the items (Craik \& Lockhart, 1972; Gibbs, 1994). Because comprehensibility judgments were not of theoretical interest in this experiment, the results were not recorded for use.

In the second part of the experiment, the subjects were given a surprise cued-recall test. They were shown either the tenors or the vehicles of statements they had seen. Half of the subjects received the tenors as cues, and half received the vehicles. These two types of cues were used because previous researchers had suggested that they might yield different performances on memory tests, with vehicles perhaps leading to better recall than tenors (Verbrugge \& McCarrell, 1977). The cues appeared on the computer screen one at a time and in a different random order than that in which they had appeared in the first part of the experiment. The subjects were instructed to write down, on a separate sheet of paper, the full statement corresponding to each cue. Moreover, they were told that they had to remember the sentences as accurately as possible. If they saw a statement as a metaphor, they had to write it as a metaphor. If they saw it as a simile, they had to write it as a simile.

In the third part, the subjects were shown the same sentences as those that they had seen in the first part of the experiment, but in a different random order. The sentences appeared one at a time. The subjects were asked to judge, for each statement, the aptness of the comparison involved. Aptness was defined as the extent to which a comparison manages to capture salient properties of the topic. For example, the subjects were told that a statement such as "a train is like a worm" may not be very appropriate, because the comparison between trains and worms does not seem to capture many of the salient features of trains, such as their strength and power. However, a statement such as "oil is like liquid gold" may seem very appropriate, because the comparison does seem to capture many of the salient features of oil, such as its value and rarity. The subjects had to indicate by keypress the aptness of each comparison by using a scale from I (very inappropriate) to 7 (very appropriate). Responses were recorded by computer.

\section{Results and Discussion}

We will begin by discussing the results of the aptness judgment task. The mean aptness rating for the comparisons was $4.36(S D=1.00)$ when they were expressed as metaphors and $4.52(S D=1.11)$ when they were expressed as similes, for a difference of 0.17 . This difference was not significant when analyzed by subject $[t(45)=$ 1.53 , n.s.]. It was also not significant when analyzed by item $[t(29)=1.90$, n.s. $]$. Hence, the form of the comparison did not affect the aptness judgment.

Form may not affect aptness, but does aptness affect form? Mean aptness ratings were calculated for each of the comparisons, averaging the aptness for the comparisons expressed as metaphors and that for the comparisons 
expressed as similes. The means are listed in Table 1. The relation between aptness and preference for comparison type was examined by relating the mean aptness ratings generated in Experiment 2 to the preferences for metaphors estimated in Experiment 1 (which ranged from .03 to .97 ). The correlation between the mean aptness ratings and the preference for metaphors was $.75(p<$ .005 ). Thus, the higher the aptness of a comparison, the more likely it was that it was preferred as a metaphor rather than as a simile.

We turn now to the recall data. First, let us ask about cue type. Did cuing by vehicle lead to better recall than cuing by tenor? Collapsing across comparison type (i.e., metaphor or simile), the proportion of statements correctly recalled when subjects were cued by topic was $.50(S D=$ $.16)$. When the subjects were cued by vehicle, the proportion of statements correctly recalled was $.53(S D=$ .18). This difference was not significant when analyzed by subject $[t(44)=-.73$, n.s. $]$. It also was not significant when analyzed by items $[t(29)=.94$, n.s. $]$. Therefore, the following analyses collapse across cue type.

Next, we examine whether there was an effect of comparison type. The results (see Table 2) were as follows: The mean proportion of similes correctly recalled was $.45(S D=.22)$, whereas the mean proportion of metaphors correctly recalled was $.58(S D=.24)$, for a difference of .13. A subject analysis revealed that this difference was significant $[t(45)=2.81, p<.01]$. The results were also significant when analyzed by item $[t(29)=$ $3.16, p<.01]$. Metaphors were better recalled than similes. This difference in performance, however, pertains to the form of the comparisons, not to their content. That is, it pertains to whether they are correctly recalled as metaphors or as similes, not to whether the subjects recalled the correct tenor or vehicle. If we disregard whether people used the correct metaphor or simile indicators to complete the statements in the cued-recall task, the proportion of comparisons presented as metaphors correctly recalled was $.79(S D=.15)$, whereas the proportion of comparisons presented as similes correctly recalled was $.76(S D=.15)$. This difference was not significant when analyzed by subject $[t(45)=0.93$, n.s. $]$, and it was not significant when analyzed by item $[t(29)=1.16$, n.s. $]$.

The better memory for metaphors arose because the subjects were more likely to misrecall a simile as a meta- phor than they were to misrecall a metaphor as a simile (see Table 2). The mean proportion of similes misrecalled as metaphors was $.31(S D=.16)$, whereas the mean proportion of metaphors misrecalled as similes was .21 $(S D=.18)$, for a difference of 10 . This was significant when analyzed by subject $[t(45)=2.56, p<.05]$ and also when analyzed by item $[t(29)=2.47, p<.05]$. Thus, there was an overall bias toward reporting metaphors rather than similes in the recall task.

This pattern of results held for 22 of the items. For example, "nature is (like) a laboratory," "life is (like) a journey," "surgeons are (like) butchers," and "cigarettes are (like) time bombs" tended to be misrecalled as metaphors more often than as similes. However, it is important for our argument that the tendency to recall similes as metaphors failed to hold for 8 of the items. The eight exceptions are the following statements: "arguing is (like) war," "people are (like) doors," "words are (like) daggers," "ideas are (like) diamonds," "hearts are (like) closets," "highways are (like) snakes," "sermons are (like) sleeping pills," and "tree trunks are (like) straws." Reversing the general trend, the subjects tended to misrecall these 8 as similes rather than as metaphors.

Can the relative proportion of the two kinds of errors (i.e., misrecalling a metaphor as a simile vs. misrecalling a simile as a metaphor) be predicted from the aptness of the comparisons? A Mann-Whitney $U$ analysis showed that the 22 items for which similes were misrecalled as metaphors more often than the reverse tended to be ranked higher in aptness than the 8 items that reversed this pattern. The mean rank for the 8 items that reversed the pattern was 10.25 , whereas for the 22 items that displayed the trend, the mean rank was 17.41 ( $U$ corrected for ties $=46.0, p<.05$ ). In short, the items that were biased toward being recalled as metaphors were higher in aptness than were those that were biased toward being recalled as similes. ${ }^{1}$

A second way to examine the biases in recall is to ask whether the preference judgments in Experiment 1 correlate with the recall effects in Experiment 2. Preference for metaphors ranged from .97 to .03 . It can be related to the proportion of metaphors misrecalled as similes and, separately, to the proportion of similes misrecalled as metaphors, in Experiment 2. If the preference can predict recall performance, it should be positively correlated

Table 2

Memory for Metaphors and Similes on a Cued-Recall Task

\begin{tabular}{|c|c|c|c|c|c|c|c|}
\hline \multicolumn{2}{|c|}{$\begin{array}{l}\text { Proportion of } \\
\text { Metaphors } \\
\text { Correctly } \\
\text { Recalled } \\
\end{array}$} & \multicolumn{2}{|c|}{$\begin{array}{c}\text { Proportion of } \\
\text { Similes } \\
\text { Correctly } \\
\text { Recalled } \\
\end{array}$} & \multicolumn{2}{|c|}{$\begin{array}{c}\text { Proportion of } \\
\text { Metaphors } \\
\text { Misrecalled } \\
\text { as Similes } \\
\end{array}$} & \multicolumn{2}{|c|}{$\begin{array}{c}\text { Proportion of } \\
\text { Similes } \\
\text { Misrecalled } \\
\text { as Metaphors }\end{array}$} \\
\hline$p$ & $S D$ & $p$ & $S D$ & $p$ & $S D$ & $p$ & $S D$ \\
\hline .58 & .24 & .45 & .22 & .21 & .18 & .31 & .16 \\
\hline
\end{tabular}

Note-The proportion of metaphors correctly recalled is significantly greater than the proportion of similes correctly recalled $(p<.01)$. The proportion of similes misrecalled as metaphors is significantly greater than the proportion of metaphors misrecalled as similes $(p<.05)$. 
with the tendency to misrecall similes as metaphors and negatively correlated with the tendency to misrecall metaphors as similes. This is, indeed, what was found. There are two analyses to perform here, it should be noted. A set of stimuli was presented in metaphor form. We can ask if the errors recalling the metaphor-form stimuli are predicted by preference judgments from Experiment 1 . Also, a set of stimuli were presented as similes. We can ask very much the same question: Are errors on those stimuli related to the preference judgments?

The correlation between the proportion of subjects preferring a comparison as a metaphor in Experiment 1 and the proportion of similes misrecalled as metaphors in Experiment 2 was $.59(p<.005)$. The correlation between the proportion of subjects preferring a comparison as a metaphor in Experiment 1 and the proportion of metaphors misrecalled as similes in Experiment 2 was $-.37(p<.05)$. Thus, the higher the preference for the metaphor form in Experiment 1, the more likely it was that similes were misrecalled as metaphors and the less likely it was that metaphors were misrecalled as similes in Experiment 2.

In short, there are key relations between aptness, preference, and recall across the two experiments. Notably, the aptness ratings in the second experiment predicted preferences for metaphors and similes in the first experiment. Moreover, the aptness ratings and the preferences for metaphors and similes predicted performance on a surprise cued-recall task. Those items that were likely to be misrecalled as similes tended to be of lower aptness than those items that were likely to be misrecalled as metaphors. They also tended to be preferred as similes rather than as metaphors.

\section{GENERAL DISCUSSION}

Evidently, it matters how a comparison is expressed. Preference for the form of a comparison is not idiosyncratic. Some comparisons were preferred as metaphors, others as similes, and for some there was no clear preference for either form of the comparison. This suggests that there is a scale of some kind at work. Indeed, preference for metaphors and similes in Experiment 1 could be predicted from the aptness of the comparisons in Experiment 2 , with higher aptness yielding a preference for metaphors and lower aptness yielding a preference for similes. Furthermore, aptness was related to performance on a cognitive task-namely, recall of the comparisons as metaphors or as similes, although not as tenor-vehicle pairs. High aptness encouraged false recall as a metaphor, whereas low aptness favored misrecall as a simile.

We should note that, although the overall bias was for similes in Experiment 1, the overall bias was for metaphors in Experiment 2. Although the subjects tended to prefer the similes in the first experiment, in the second experiment, the subjects were more likely to misrecall the similes as metaphors than the reverse. This suggests that a second factor is in play, in addition to aptness. It could be that recall favors brevity and, therefore, the metaphor (which omits the word like) rather than the simile, as Aristotelian theory contends. However, what matters most for our argument about aptness is not the overall preference for metaphors or similes but, rather, whether the scale of preferences and biases in one experiment can predict those in the other. Indeed, we found that preference for metaphors and similes in Experiment 1 predicted the biases in recalling metaphors and similes in Experiment 2 . The more likely it was that items were preferred as metaphors in Experiment 1, the more likely it was that they were misrecalled as metaphors in Experiment 2.

Our results help to shed light on an interesting finding by Harris, Tebbe, and Leka (1999). They presented subjects with a list of metaphors and similes, which was followed by a cued-recall task. The subjects were either English speakers or Spanish speakers, and the items were presented in their native languages. The Spanish statements were translations of the English items. They found that the English-speaking subjects were more likely to misrecall the similes as metaphors, whereas Spanishspeaking subjects were more likely to misrecall the metaphors as similes. Thus, English subjects were biased toward metaphors, whereas Spanish subjects were biased toward similes. Our present experiments suggest that this difference in performance may be due to comparison aptness. That is, the items translated into Spanish may not have been as apt as their English counterparts, and this could have influenced the performance on the recall task. Although the experimenters did not assess aptness, the results of the present experiments suggest that future research along these lines should control for comparison aptness.

The results of the present experiments are relevant to theories of metaphor. The traditional theory of metaphor (called the comparison theory), which goes back to Aristotle, makes two claims about the relation between metaphors and similes. First, it holds that metaphors are simply similes with the term of comparison (like) left out (Billow, 1977; Fogelin, 1988; Ortony, 1979a, 1979b). If so, metaphors are just compact similes. Second, a modern version, in which processing order is considered, holds that metaphors are converted into similes during comprehension (Glucksberg \& Keysar, 1990, 1993; Kintsch, 1974; Miller, 1979; Searle, 1979).

The rationale for the modern version of Aristotle's theory is as follows. Superficially, metaphors often seem to assert something absurd. For example, "rumors are weeds" is absurd, because rumors cannot be weeds. They are not plants, they do not grow on your lawn, and so on. The Aristotelian theory holds that people resolve the absurdity by converting metaphors into corresponding similes. The similes are not absurd, because, for example, rumors can be like weeds in certain respects without being like weeds in all respects. In the standard version of this theory, people comprehend the similes by engaging in a comparison, searching for relevant properties of the vehicle that underwrite the similarity between the vehicle 
and the tenor (Chiappe, 1998). For example, people would search for properties of weeds that are applicable to rumors, such as that they spread very quickly, are hard to get rid of, and so on.

The present experiments are inconsistent with the Aristotelian comparison theory in two ways. First, the comparison theory has trouble with the finding that the preference for expressing comparisons as metaphors and as similes can be related to their aptness. If metaphors are short forms of similes, there is no basis for choosing one form over the other as far as the aptness of the comparisons is concerned. The preference should be guided by whether or not one wants to be concise.

Second, the Aristotelian comparison theory predicts that metaphors should be misrecalled as similes more often than the reverse, because metaphors are converted into similes during comprehension. If "rumors are weeds" is converted into "rumors are like weeds" during comprehension, people should be more likely to say that they saw "rumors are like weeds" when they saw "rumors are weeds" than to say that they saw "rumors are weeds" when they saw "rumors are like weeds." Thus, the comparison theory predicts a pattern of results that is opposite to the one observed in Experiment 2. The subjects were much more likely to misrecall similes as metaphors than they were to misrecall metaphors as similes.

If metaphors are not understood by being converted into similes, as Aristotle's theory maintains, how are they understood? Glucksberg and Keysar (1990, 1993; see also Glucksberg, 1995) have offered an alternative theory, known as the class-inclusion model. This theory holds that metaphors are class-inclusion statements (like "this is furniture"), not identity statements (like "this is Jim"). What distinguishes metaphors from other class-inclusion statements is that the categories involved are, to use Barsalou's $(1983,1991)$ term, ad hoc categories. These are categories that are "not established in memory but derived impromptu to achieve a current goal" (Barsalou, 1991, p. 1). Examples include "departure times that minimize work disruption," "people to visit in California," and "things to pack in a small suitcase" (Barsalou, 1991).

Glucksberg and Keysar (1990, 1993) claim that metaphors assert that the tenor belongs to an ad hoc category. However, instead of the speaker defining the ad hoc category explicitly by listing its criteria, the category is indicated by its prototypical exemplar. For example, consider the metaphor "my job is a jail." In this case, the person is claiming that his or her job belongs to the ad hoc category of things that share the following properties: "They are unpleasant, confining, and stifling; people are there against their will; it is difficult to get out of them; they are not rewarding; and so forth" (Glucksberg \& Keysar, 1990 , p. 7). However, instead of simply saying that their job belongs in this category, they mention the stereotypical member of the category, using the word "jail." Thus, "jail" is used to stand for the ad hoc category that it exemplifies.
Metaphor comprehension, according to this theory, involves recovering the ad hoc category exemplified by the vehicle. How is this done? Noting the fact that a statement is a categorization claim does not ipso facto tell us what the relevant category is (Kennedy \& Chiappe, 1999). Presumably, one has to engage in a comparison, looking for properties of the vehicle applicable to the tenor. Indeed, the ad hoc category is constituted by a set of properties, and the only way of determining what those properties are is by comparing the tenor to the vehicle. If so, there is little that distinguishes the class-inclusion model from the comparison theory. The difference boils down to the denial that metaphors are converted into similes prior to engaging in a comparison process. Metaphors instruct people to engage in a comparison process, as similes do (although metaphors may ask one to notice a greater number of common properties, as Glucksberg \& Keysar [1990, 1993] suggest).

Interestingly, Glucksberg and Keysar (1990, 1993) do not claim that metaphors and similes are different ways of getting people to notice cummon properties. Rather, Glucksberg and Keysar argue that similes are understood by being converted into class-inclusion statements. They say, "similes are . . implicit category statements" (1990, p. 12). And, " $S$ is like $P$ will ... be converted ... into the original metaphor form, $S$ is $P$ " (1993, p. 408). Once similes are converted into metaphors, people search for the ad hoc category involved. Evidently, on this view, it is only after similes are converted into metaphors that people search for the ad hoc category involved in the statement.

Gluckberg and Keysar's (1990, 1993) claim that similes are converted into metaphors during comprehension is consistent with the findings of the present experiments. If similes are converted into metaphors, one would expect that, in general, similes would be misrecalled as metaphors more often than the reverse. Indeed, this is what we found. It is possible, then, that the overall bias for misrecalling comparisons as metaphors was due to the fact that similes were converted into metaphors.

We remain skeptical at this point, however. For one, we did not find a tendency to misrecall similes as metaphors for all of the items. For some items, the reverse pattern was observed, and the key factor seems to be comparison aptness. We stress that, as aptness decreased, preference for metaphors switched to preference for similes. It was not just that the effect of aptness faded as aptness waned. Rather, at low levels, aptness fitted with the simile form. Moreover, the findings of the Harris et al. (1999) experiment, discussed above, are inconsistent with the assumption that similes are converted into metaphors. If similes are converted into metaphors, there should have been a general tendency to misrecall similes as metaphors, not just in English, but in Spanish as well. However, the Spanish items tended to be misrecalled as similes more often than the reverse. Furthermore, converting a sentence in one form (a simile) into another sentence 
(a metaphor) seems to be an irrelevant step. It makes litthe sense to convert a simile into a metaphor, if one has to engage in a comparison process anyway. Why not directly engage in a comparison process when one sees a simile? What could be gained by converting the statement into a metaphor? Glucksberg and Keysar's (1990, 1993) account fails to make this clear.

A possible defense of the Glucksberg and Keysar (1990, 1993) position is as follows: Could it be that some comparisons make sense and others do not and that Glucksberg and Keysar's theory applies only to those that make sense? "Laser printers are hot dogs" to many might make no sense. Some people may wish to express such statements as similes. They might reason that they should not commit themselves to nonsensical claims. They might go on to conjecture that the simile involves less of a commitment (and they might be biased to remember nonsensical metaphors as similes for the same reason). Thus, the apparent reversal for some comparisons of what Glucksberg and Keysar might predict may actually be a reflection of how people cope with nonsensical metaphors.

To check this interesting argument about nonsensical metaphors, consider the comparisons that our subjects recalled as similes. They included "arguing is like war" and "sermons are like sleeping pills." These are not nonsensical. Consider, too, the comparisons that were strongly preferred as similes. They included "highways are like snakes" and "tree trunks are like straws." These, too, are far from nonsense. In addition, comparisons that were not at the extreme in preference as similes but, nonetheless, were preferred as similes to some extent, are very far from being nonsense. Comparisons that were modestly preferred as similes included "salesmen are like bulldozers," "man is like a wolf," and "jobs are like jails." The first two are certainly not nonsense. The third is one devised by Glucksberg and Keysar, and we would not call it nonsense.

One further problem with the nonsense-comparison argument may be worth noting. Comparisons preferred as similes may be quite sensible ones. But in some instances, the same comparisons expressed as metaphors may appear to make less sense. Consider "treetrunks are straws" and "tree trunks are like straws." It may be that the simile version is sensible and the metaphor is puzzling. The same applies to "highways are snakes" and "highways are like snakes." The simile seems to make more sense. We conjecture that the fault lies not in the particular comparisons but, rather, in a more general reason having to do with aptness-perhaps a low-aptness comparison expressed in the less-preferred fashion (i.e., as a metaphor) appears to be less sensible. In sum, the argument about nonsensical claims is intriguing but faces serious difficulties.

To conclude, Glucksberg and Keysar $(1990,1993)$ and Roberts and Kreuz (1994) have provided grounds for our claim that metaphors are preferred when a comparison is particularly apt and that similes are preferred when a comparison is not as apt. Moreover, Glucksberg and Keysar may be right that metaphors are class-inclusion state- ments, where the vehicle is the prototypical exemplar of an ad hoc category. There is little reason to believe, however, that similes are converted into metaphors during comprehension. We maintain that similes, like metaphors, are instructions to find relevant common properties between tenors and vehicles. A priori, we see no need to convert one form of the comparison into another prior to engaging in a comparison process.

\section{REFERENCES}

Aristotle (1926). The art of rhetoric. New York: Putnam's.

BarsaloU, L. W. (1983). Ad hoc categories. Memory \& Cognition, 11, 211-227.

Barsalou, L. W. (1991). Deriving categories to achieve goals. In G. H. Bower (Ed.), The psychology of learning and motivation (Vol. 27, pp. 1-64). San Diego, Academic Press.

Bartlett, F. C. (1932). Remembering. Cambridge: Cambridge University Press.

BILLow, R. M. (1977). Metaphor: A review of the psychological literature. Psychological Bulletin, 84, 81-92.

BLACK, M. (1979). More about metaphor. In A. Ortony (Ed.), Metaphor and thought (pp. 19-43). Cambridge: Cambridge University Press.

ChiAPPE, D. L. (1998). Similarity, relevance, and the comparison process. Metaphor \& Symbol, 13, 17-30.

Craik, F. I. M., \& LockHarT, R. (1972). Levels of processing: A framework for memory research. Journal of Verbal Learning \& Verbal Behaviour, 11, 671-684.

Dawkins, R. (1986). The blind watchmaker. New York: Penguin.

Fogelin, R. (1988). Figuratively speaking. New Haven, CT: Yale University Press.

GeNTNER, D. (1983). Structure-mapping: A theoretical framework for analogy. Cognitive Science, 7, 155-170.

GentNER, D. (1989). The mechanisms of analogical learning. In S. Vosniadou \& A. Ortony (Eds.), Similarity and analogical reasoning (pp. 199-241). Cambridge, MA: Cambridge University Press.

GentNer, D., \& Clement, C. (1988). Evidence for relational selectivity in the interpretation of analogy and metaphor. In G. H. Bower (Ed.), The psychology of learning and motivation (Vol. 22, pp. 307358). San Diego: Academic Press.

Gentner, D., \& Markman, A. B. (1997). Structure mapping in analogy and similarity. American Psychologist, 52, 45-56.

GiBbS, R. W. (1994). The poetics of mind. New York: Cambridge University Press.

GluCKSBERG, S. (1995). Commentary on nonliteral language: Processing and use. Metaphor \& Symbolic Activity, 10, 47-57.

GlucksberG, S., \& Keysar, B. (1990). Understanding metaphorical comparisons: Beyond similarity. Psychological Review, 97, 3-18.

GluCkSBERG, S., \& KeYSAR, B. (1993). How metaphors work. In A. Ortony (Ed.), Metaphor and thought (2nd ed., pp. 401-424). Cambridge: Cambridge University Press.

Harris, R., Tebbe, M., \& LekA, G. (1999). Memory for concrete and abstract metaphors and similes in English and Spanish. Metaphor ca Symbol, 14, 1-I6.

KaTZ, A. (1989). On choosing the vehicles of metaphors. Journal of Memory \& Language, 28, 486-499.

KATZ, A. (1992). Psychological studies of metaphor processing: Extensions to the placement of terms in semantic space. Poetics Today, 13, 607-632.

KenNedy, J. M.. \& ChiAPPE, D. L. (1999). What makes a metaphor stronger than a simile? Metaphor \& Symbol, 14, 63-70.

KINTSCH, W. (1974). The representation of meaning in memory. Hillsdale, NJ: Erlbaum.

MALGADY, R., \& JoHnSON, M. (1976). Modifiers in metaphors: Effects of constituent phrase similarity on the interpretation of figurative sentences. Journal of Psycholinguistic Research, 5, 43-52.

MiLl.eR, G. A. (1979). Images and models, similes and metaphors. In A. Ortony (Ed.), Metaphor and thought (pp. 202-250). Cambridge: Cambridge University Press.

MORGAN, J. L. (1979). Observations on the pragmatics of metaphor. In 
A. Ortony (Ed.), Metaphor and thought (pp. 136-147). Cambridge: Cambridge University Press.

NeIsser, U. (1967). Cognitive psychology. New York: Appleton-CenturyCrofts.

Ortony, A. (1975). Why metaphors are necessary and not just nice. Educational Theory, 25, 45-53.

OrTONY, A. (1979a). Beyond literal similarity. Psychological Review, 86, $161-180$.

OrTONY, A. (1979b). The role of similarity in similes and metaphors. In A. Ortony (Ed.), Metaphor and thought (pp. 186-201). Cambridge: Cambridge University Press.

RICHARDS, I. A. (1936). The philosophy of rhetoric. New York: Oxford University Press.

Roberts, R. M., \& Kreuz, R. J. (1994). Why do people use figurative language? Psychological Science, 5, 159-163.

SCHACTER, D. (1995). Memory distortion: History and current status. In D. Schacter (Ed.), Memory distortion: How minds, brains, and societies reconstruct the past (pp, 1-43). Cambridge, MA: Harvard University Press.

SeARle, J. R. (1979). Metaphor. In A. Ortony (Ed.), Metaphor and thought (pp. 92-123). Cambridge: Cambridge University Press.

Tourangeau, R., \& STerngerg, R. (1981). Aptness in metaphor. Cognitive Psychology, 13, 27-55.

Tourangeau, R., \& Sternberg, R. (1982). Understanding and appreciating metaphors. Cognition, 11, 203-244.

Trick, L., \& KATZ, A. (1986). The domain interaction approach to meta- phor processing: Relating individual differences and metaphor characteristics. Metaphor \& Symbolic Activity, 1, 185-213.

Tversky, A. (1977). Features of similarity. Psychological Review, 84, 327-352.

Verbrugge, R., \& MCCARRELL, N. (1977). Metaphoric comprehension:

Studies in reminding and resembling. Cognitive Psychology, 9, 494-533.

\section{NOTE}

1. One might argue that, because the aptness ratings were collected after the subjects completed the recall task, the recall task could contaminate the aptness ratings. However, it is unlikely that this happened. A separate group of 16 subjects (volunteers from an introduction to psychology class at the University of Toronto, mean age of 19 years) was given metaphors and similes and was asked to rate the comparisons for comprehensibility and then for aptness. The subjects saw half of the comparisons as similes and half as metaphors, and each subject had a different random order of the comparisons. The correlation between the mean aptness ratings for each comparison generated by this group of subjects and those generated by the subjects in Experiment 2 was .86 $(p<.005)$. Thus, the aptness ratings appear to be reliable, presenting similar patterns with and without an intervening recall task.

(Manuscript received July 16, 1998;

revision accepted for publication December 18,1998 .) 